\title{
1 BORCS6 is involved in the enlargement of lung lamellar bodies in Lrrk2 knockout
}

2 mice

3

4 Miho Araki ${ }^{1}$, Sho Takatori $^{1}$, Genta Ito $^{2 *}$, and Taisuke Tomita ${ }^{1,2 *}$

5

6 1. Laboratory of Neuropathology and Neuroscience, Graduate School of

7 Pharmaceutical Sciences, The University of Tokyo, Tokyo 113-0033, Japan

2. Social Cooperation Program of Brain and Neurological Disorders, Graduate School of Pharmaceutical Sciences, The University of Tokyo, Tokyo 113-0033, Japan

\section{ORCID identifiers:}

12 Miho Araki, 0000-0002-9516-6868

13 Sho Takatori, 0000-0002-3925-4011

14 Genta Ito, 0000-0001-6370-1099

15 Taisuke Tomita, 0000-0002-0075-5943

\section{*Corresponding authors:}

Genta Ito

Social Cooperation Program of Brain and Neurological Disorders, Graduate School of

Taisuke Tomita 
bioRxiv preprint doi: https://doi.org/10.1101/2021.03.05.434068; this version posted March 5, 2021. The copyright holder for this preprint (which was not certified by peer review) is the author/funder, who has granted bioRxiv a license to display the preprint in perpetuity. It is made available under aCC-BY-NC-ND 4.0 International license.

26 Laboratory of Neuropathology and Neuroscience, Graduate School of Pharmaceutical

27 Sciences, The University of Tokyo, 7-3-1 Hongo, Bukyoku, Tokyo 113-0033, Japan

28 Phone: $+81-(0) 3-5841-4868$

29 Email: taisuke@mol.f.u-tokyo.ac.jp

30 


\section{Abstract (175 words)}

Leucine-rich repeat kinase 2 (LRRK2) has been implicated in the pathogenesis of Parkinson disease. It has been shown that Lrrk2 knockout (KO) rodents have enlarged lamellar bodies (LBs) in their alveolar epithelial type II cells, although the underlying mechanisms remain unclear. Here we performed proteomic analyses on LBs isolated from Lrrk2 $\mathrm{KO}$ mice and found that the LB proteome is substantially different in Lrrk2 $\mathrm{KO}$ mice compared with wild-type mice. In Lrrk2 KO LBs, several Rab proteins were increased, and subunit proteins of BLOC-1-related complex (BORC) were decreased. The amount of surfactant protein $\mathrm{C}$ was significantly decreased in the bronchoalveolar lavage fluid obtained from Lrrk2 KO mice, suggesting that LB exocytosis is impaired in Lrrk2 $\mathrm{KO}$ mice. We also found that the enlargement of LBs is recapitulated in A549 cells upon KO of $L R R K 2$ or by treating cells with LRRK2 inhibitors. Using this model, we show that $\mathrm{KO}$ of BORCS6, a BORC subunit gene, but not other BORC genes, causes LB enlargement. Our findings implicate the LRRK2-BORCS6 pathway in the maintenance of LB morphology.

\section{Keywords:}

BLOC-1-related complex subunit 6/leucine-rich repeat kinase 2/lung lamellar body 


\section{Introduction}

Parkinson disease (PD) is a neurodegenerative disorder characterized by the selective loss of dopaminergic neurons in the substantia nigra, Lewy body formation in the remaining neurons, and the impairment of motor functions, including bradykinesia, rigidity, resting tremor, and postural instability (Sveinbjornsdottir, 2016). Leucine-rich repeat kinase 2 (LRRK2) has been identified as one of the most common genetic causes of familial PD (Paisán-Ruíz et al, 2004; Zimprich et al, 2004). Genome-wide association studies identified the association of the $L R R K 2$ locus with an increased risk of sporadic PD (Satake et al, 2009; Simón-Sánchez et al, 2009).

LRRK2 consists of 2,527 amino acids, and contains several functional domains, such as a guanosine triphosphate (GTP)-binding domain and a kinase domain (Civiero et al, 2012; Mills et al, 2012; Vancraenenbroeck et al, 2012). It has been suggested that LRRK2 is involved in autophagy, intracellular vesicle trafficking, inflammatory responses, and synaptic transmission (Araki et al, 2018). Recently, small Rab GTPases, including Rab3A/B/C/D, Rab5, Rab8A/B, Rab10, Rab12, Rab35, and Rab43 have been identified as physiological substrates of LRRK2 (Steger et al, 2016; Ito et al, 2016). LRRK2 phosphorylates these proteins at a serine or threonine residue within their switch II domain, thereby regulating the interaction of Rab proteins with their regulatory factors as well as effector proteins. Phosphorylation of these Rab proteins by LRRK2 has been shown to regulate various cellular functions, including the regulation of primary cilia, lipid storage, and the homeostasis of stressed lysosomes (Yu et al, 2018; Eguchi et al, 2018; Steger et al, 2017).

LRRK2 is highly expressed in the brain, kidney, lung, and immune cells (Giasson et al, 2006). Although Lrrk2 knockout (KO) mice did not show any notable changes in the 
brain, a substantial enlargement of secondary lysosomes in renal proximal tubule cells and lung lamellar bodies (LBs) in alveolar epithelial type 2 (AT2) cells was observed (Herzig et al, 2011). Moreover, mice, rats, as well as nonhuman primates administered with selective LRRK2 kinase inhibitors showed a similar enlargement of LBs in AT2 cells (Fuji et al, 2015; Harney et al, 2020; Andersen et al, 2018). These observations led us to hypothesize that LRRK2 plays an important role in regulating LBs. LB enlargement was observed in Rab38 KO mice, presumably due to a decrease in LB exocytosis (Osanai et $a l$, 2010). However, the molecular mechanisms underlying the enlargement of LBs in Lrrk2 KO mice remains unknown.

Pulmonary surfactant is a mixture of proteins and lipids, and forms a layer on the surface of alveoli to prevent them from collapse during respiration. Lung LBs play an important role in the synthesis, storage, and secretion of pulmonary surfactant (Wadsworth et al, 1997). LBs are lysosome-related organelles that exist specifically in lung AT2 cells (Weaver et al, 2002). Similar to lysosomes, LBs express lysosomalassociated membrane protein 1 (LAMP1) and CD63, contain soluble degradative enzymes, such as cathepsin C, and have an acidic pH (Hook \& Gilmore, 1982). Although the molecular mechanisms of LB exocytosis are not fully understood, lysosomal exocytosis has been relatively well studied. Lysosomal exocytosis requires two sequential steps; i.e., transport to the cell periphery, and fusion with the plasma membrane (Encarnação et al, 2016). Recent studies have reported that biogenesis of lysosomerelated organelles complex (BLOC) one-related complex (BORC) plays an essential role in the anterograde transport of lysosomes ( $\mathrm{Pu}$ et al, 2015). Given the similarities of LBs to lysosomes, it is possible that LB exocytosis also depends on BORC.

Therefore, in this study we performed proteomic analysis on mouse LBs isolated 
98 from wild-type (WT) and Lrrk2 KO mice. Our results showed that in Lrrk2 KO mice,

99 several Rab proteins, including Rab3A, Rab3D, and Rab27A were significantly increased,

100 and subunit proteins of BORC, including Borcs6, were significantly decreased.

101 Furthermore, we established a cellular model in A549, a cancer cell line that originated

102 from a human lung, to evaluate LB enlargement. Using these cells, we observed LB

103 enlargement in BORCS6 KO cells. This effect was rescued by BORCS6 overexpression.

104 Our results hence demonstrated that BORCS6 plays an important role in maintaining the 105 morphology of LBs. 


\section{Results and Discussion}

\section{Lamellar body enlargement in Lrrk2 KO mice}

Although several studies have demonstrated that LBs existing in AT2 cells are enlarged in Lrrk2 KO rodents (Herzig et al, 2011), this has not been validated quantitatively. Therefore, we performed electron microscopy on the lung of 2-month-old mice (Figure 1A). In Lrrk2 KO mice, we found that LBs occupied most of the cytoplasm of AT2 cells, and other organelles were hardly observed. The area occupied by LBs in the electron micrographs was significantly increased in Lrrk2 $\mathrm{KO}$ mice compared with WT mice (Figure 1B). These results indicate that LBs of Lrrk2 KO mice are significantly larger than those of WT mice. In Lrrk2 KO mice, the levels of surfactant protein C (Sftpc)

117 in the bronchoalveolar lavage fluid (BALF) measured by the enzyme-linked immunosorbent assay were significantly decreased compared with WT mice (Figure 1C). As Sftpc is secreted by the exocytosis of LBs, this result suggested that LB exocytosis is impaired in Lrrk2 KO mice.

\section{Isolation of lamellar bodies from Lrrk2 $\mathrm{KO}$ mice}

Given that LRRK2 is involved in the regulation of intracellular trafficking, we hypothesized that proteins responsible for the enlargement of LBs might have an altered localization to/from LBs in Lrrk2 KO mice. To elucidate this hypothesis, we performed liquid chromatography-tandem mass spectrometry (LC-MS/MS) analysis on LBs isolated from mouse lungs. We isolated LBs by sucrose gradient centrifugation (Figure 2A) and confirmed the enrichment of LBs in one of the fractions by immunoblotting (Figure 2B). As a marker of LBs, we used ATP-binding cassette sub-family A member 3 (Abca3), which is an $\mathrm{ABC}$ transporter that specifically localizes to LB membranes. We also 
analyzed the expression of phospholipid-transporting ATPase IA (Atp8a1) as well as expressed in the LB membranes (Ridsdale et al, 2011). We used Rab5 and receptorbinding cancer antigen expressed on SiSo cells (Rcas1) as markers of early endosomes and the Golgi apparatus, respectively. LB proteins were detected in the 0.4 to $0.5 \mathrm{M}$ sucrose fraction (Figure 2B; lane 8), whereas Rab5 and Rcas1 were not, suggesting that LBs were selectively enriched in this fraction. Notably, LRRK2 was not detected in the LB fraction (Figure 2B).

Substantial changes in the lamellar body proteome in Lrrk2 $\mathrm{KO}$ mice

Next, we performed LC-MS/MS analysis using the LB fractions isolated from 3month-old WT and Lrrk2 KO mice. Although the ratio of wet lung weight to body weight was comparable between the genotypes (Figure 2C), total amount of proteins in the LB fraction was significantly increased in Lrrk2 KO mice (Figure 2D). The LC-MS/MS analysis identified approximately 1,500 proteins from the LB fraction, and several proteins specifically expressed in LBs, including Sftpb, Sftpc, and Abca3 were shown to be highly enriched, indicating that the LB proteome was successfully acquired (Dataset

S1). Label-free quantification demonstrated that 93 proteins were significantly increased by more than 2 -fold, and 74 proteins were decreased by less than 0.5 -fold in the Lrrk 2 KO mouse LB fraction compared with the corresponding fraction from WT mice (Figure 2E).

To further confirm genotype-dependent changes, z-scores were calculated based on 
the level of each protein quantified in the LC-MS/MS analysis. Clustering analysis based on the z-scores of differentially detected proteins separated the genotypes (Figure 2F). These results suggested that the LB proteome was robustly different between Lrrk2 KO mice and WT mice.

Gene ontology (GO) enrichment analysis demonstrated that several GO terms, including "small GTPase mediated signal transduction", were significantly enriched among proteins increased in Lrrk2 KO LBs (Figure S1A). We also noticed that a large number of Rab GTPases were significantly increased in the Lrrk2 KO LBs (Dataset S1), some of which have previously been shown to be physiologically phosphorylated by LRRK2 (Steger et al, 2017). Proteins decreased in Lrrk2 KO LBs had GO terms including "negative regulation of peptidase activity", "anterograde synaptic vesicle transport", "lysosome localization", "blood coagulation hemostasis", "anterograde axonal transport", and "innate immune response" (Figure S1B). Interestingly, subunit proteins of BORC, including Bloc1s2, Snapin, Borcs5/Loh12cr1, Borcs6/C17orf59, and BORCS7/C10orf32, and subunits of late endosomal/lysosomal adaptor, MAPK and mTOR activator (LAMTOR), including Lamtor1, Lamtor4, and Lamtor5, were significantly decreased in Lrrk2 KO LBs (Figure 2E, Dataset S1). These results suggested that BORC functions in regulating the size of LBs downstream of LRRK2.

Collectively, based on the results of our proteomic analysis of LBs, we hypothesize that the increase in Rab GTPases and/or the decrease in BORC on LBs are involved in the enlargement of LBs in Lrrk2 $\mathrm{KO}$ mice. 
mice

To validate the results of the LB proteomics analysis, LB fractions isolated from WT and Lrrk2 KO mice were subjected to immunoblotting. The expression levels of Rab3A, Rab3D, and Rab27A in Lrrk2 KO mouse LB fractions were significantly increased, which was consistent with the proteomics results (Figure 3A), whereas no changes were observed in the lung homogenates (Figure 4A). Borcs5 and Borcs7 were significantly decreased in the LB fractions of Lrrk2 KO mice compared with those of WT mice (Figure 3B), whereas they were unchanged in the lung homogenates (Figure 4B). Unfortunately, we were unable to perform immunoblotting analysis of Borcs6, as all commercially available antibodies for BORCS6 reacted only with human BORCS6, but not with mouse Borcs6. We also confirmed the decrease in Lamtor1 and Lamtor4, which are subunit proteins of the LAMTOR complex, in Lrrk2 KO LBs compared with WT LBs (Figure 3C), whereas they were unchanged in the lung homogenates (Figure 4C). These results successfully validated the results of our LB proteomics analysis.

\section{A cellular model of lamellar body enlargement}

To identify the protein(s) responsible for the enlargement of LBs in the absence of LRRK2, we first established a cellular model to analyze LB morphology using A549 cells. As A549 cells were derived from a human lung carcinoma, and harbor multilamellar organelles, these cells have generally been used as a model of AT2 cells (Mason \& Williams, 1980). Using the clustered regularly interspaced short palindromic repeats (CRISPR)/Cas9 technology, we generated A549 LRRK2 KO monoclonal cells (clones $\# 28, \# 104$, and \#126). Genomic sequencing confirmed that all clones have indels in the respective genes, resulting in a premature stop codon (Figure S2). Immunoblotting 
analyses confirmed that these established clones lack the endogenous expression of LRRK2 in contrast to the parental cells (Figure 5A). We also showed that the levels of phosphorylation of Rab10, which is a physiological substrate of LRRK2, were significantly decreased in LRRK2 KO clones (Figure 5A), indicating the lack of LRRK2 kinase activity in these clones. Electron microscopic observation demonstrated that LBs were enlarged in all LRRK2 KO A549 clones (Figure 5B). The area occupied by LBs in the $L R R K 2 \mathrm{KO}$ cells was significantly larger than that of the parental cells (Figure 5C).

In addition to the genetic model of LB enlargement, we also established a pharmacological model using A549 cells. A549 cells were treated with two selective LRRK2 kinase inhibitors with different chemical structures, namely GSK2578215A and MLi-2, for 1 week. We confirmed that the levels of LRRK2 phosphorylation at Ser935, which is dephosphorylated upon inhibition of LRRK2 by small compounds, were significantly decreased in A549 cells upon treatment with the inhibitors (Figure 5D). The areas occupied by LBs in cells treated with the inhibitors were significantly larger than that of vehicle-treated cells with dimethylsulfoxide (DMSO) (Figure 5E, F). Taken together, we successfully established cellular models to evaluate LB enlargement in A549 cells.

\section{BORCS6 KO caused lamellar body enlargement in A549 cells}

To elucidate whether the decrease in the amount of BORC components on LBs caused the LB enlargement in Lrrk2 KO mice, we established A549 KO clones lacking either BORCS5, BORCS6, or BORCS7. Genomic sequencing confirmed that all clones have indels in the respective genes, resulting in a premature stop codon (Figure S3). We also confirmed that BORCS5, BORCS6, and BORCS7 were not expressed in the 
corresponding $\mathrm{KO}$ clones by immunoblotting (Figure 6A-C). It has been reported that the $\mathrm{KO}$ of BORC components causes the perinuclear accumulation of LAMP1-positive vesicles (Pu et al, 2015). Whereas this phenotype was also observed in our BORCS5 KO and BORCS7 KO A549 clones, BORCS6 KO A549 cells did not show the perinuclear accumulation of LAMP1-positive vesicles (Figure 6D). Moreover, the KO of BORCS5 caused a reduction in the expression level of BORCS7 (Figure 6A) and vice versa (Figure 6C), whereas BORCS6 KO did not affect the expression levels of BORCS5 or BORCS7 (Figure 6B), suggesting that BORCS6 is dispensable for the formation of and function of BORC in A549 cells.

We next analyzed the size of the LBs in these KO cells by electron microscopy, and found that the BORCS6 KO clone \#9 has enlarged LBs (Figure 6E). Three independent BORCS6 KO monoclonal clones (i.e., \#9, \#11, and \#17) demonstrated significantly enlarged LBs (Figure 7A, B), but BORCS5 KO and BORCS7 KO A549 cells did not show significant changes in the sizes of their LBs (Figure 6E, F). Notably, LBs harboring multiple cores (i.e., multilamellar bodies) were often observed in BORCS6 KO cells (Figure 6E, Figure 7A). The phosphorylation levels of the physiological substrates of LRRK2, namely, Rab10 and Rab12, were not greatly changed in BORCS6 KO cells when analyzed by immunoblotting (Figure 7C). Lentiviral overexpression of V5-tagged BORCS6 in A549 BORCS6 KO cells restored the size of LBs to the level in A549 parental cells (Figure 7D-F), indicating that the on-target deletion of BORCS6 caused the enlargement of LBs in A549 cells. Taken together, these results suggested that BORCS6 is involved in the enlargement of LBs caused by the absence of LRRK2. 


\section{$\underline{\text { Discussion }}$}

In the present study, we quantitatively analyzed the enlargement of lung LBs in Lrrk2 $\mathrm{KO}$ mice, and systematically identified proteins differentially expressed in the LBs of Lrrk2 KO mice compared with WT mice, by label-free quantitative mass spectrometry analysis. We found that the LB proteome was substantially different in Lrrk2 KO mice compared with WT mice, and that several Rab GTPases and BORC subunits had an altered localization in Lrrk2 $\mathrm{KO}$ mice. We then established cellular models of LB enlargement by the KO or inhibition of LRRK2 in A549 cells, and we identified that the loss of BORCS6 causes LB enlargement. These results suggest that BORCS6 is involved in the regulation of the size of lung LBs, and its dissociation from LBs is responsible for the enlargement of LBs in the absence of LRRK2 activity (Figure 8).

A previous report has shown that AT2 cells primary cultured from Lrrk2 KO rats are deficient in LB exocytosis (Miklavc et al, 2014). In fact, in our study, the levels of Sftpc in BALF were significantly decreased in Lrrk2 KO mice (Figure 1C), suggesting that the exocytosis of surfactant proteins from LBs are also impaired in Lrrk2 KO mice. Eguchi and colleagues have shown that in macrophages, LRRK2 promotes lysosomal exocytosis when lysosomes are overloaded with lysosomotropic materials such as chloroquine (Eguchi et al, 2018). In this sense, it is reasonable to suppose that in AT2 cells, LRRK2 is also involved in the exocytosis of LBs. It would be interesting to investigate in the future whether the LRRK2-BORCS6 pathway also plays a role in the lysosomal stress response in macrophages.

Among the differentially regulated proteins, several Rab GTPases were significantly increased in the LB fractions of Lrrk2 KO mice (Figure 2E). These included LRRK2 substrate Rabs, such as Rab3A/D, Rab5A/B/C, Rab8A/B, and Rab10 (Steger et al, 2017), 
as well as non-LRRK2 substrate Rabs, such as Rab1A/B, Rab27A/B, Rab18, Rab6A, proteins are involved in the biogenesis of LBs; Rab3D, for example, is localized on LBs at the cell periphery, thereby facilitating their exocytosis (Van Weeren et al, 2004). Furthermore, Rab38 KO animals often show LB enlargement, implicating the involvement of Rab38 in the regulation of LB biogenesis (Osanai et al, 2010). However, further investigation is required to unequivocally identify which, if any, Rab(s) play a role in the enlargement of LBs in Lrrk2 KO mice.

BORC consists of eight proteins, namely, BORCS1 to 8 (Pu et al, 2015). BORC exists on lysosomal membranes and promotes the microtubule-dependent centrifugal transport of lysosomes (Guardia et al, 2016). Considering that the LB is a lysosomerelated organelle and shares some properties with lysosomes, its transport as well as biogenesis may be regulated by BORC. Interestingly, we found that most of the BORC subunit proteins were downregulated in Lrrk2 KO LBs (Figure 3B), whereas no changes were observed in lung homogenates (Figure 4B). This result prompted us to investigate whether BORC is involved in the enlargement of LBs. We found that $\mathrm{KO}$ of the BORC component gene BORCS6 caused enlargement of LBs in A549 cells, similarly to A549 LRRK2 KO cells (Figure 6). As the LB phenotype observed upon deletion of BORCS6 was reproducibly observed in three independent clones, and the phenotype was rescued by the re-expression of BORCS6 (Figure 7), it was clear that the on-target deletion of BORCS6 caused this phenotype. However, $\mathrm{KO}$ of the other two BORC subunits, BORCS5 and BORCS7, did not show similar effects (Figure 6). These results suggest that loss of BORC itself is not involved in the enlargement of LBs observed in the BORCS6 KO cells. 
297 BORCS6, causes the accumulation of lysosomes in the perinuclear region (Pu et al, 2015;

298 Filipek et al, 2017). In contrast, in A549 cells, whereas the KO of BORCS5 and BORCS7

299 caused the perinuclear accumulation of LAMP1-positive lysosomes, the KO of BORCS6

300 did not (Figure 6D), indicating that BORCS6 is dispensable for BORC function in A549

301 cells. These results suggest that BORCS6 may act on its own or in complex with other

302 proteins to maintain the morphology of LBs. It has been shown that BORCS6 (also known

303 as C17orf59 or Lyspersin) associates with LAMTOR on lysosomes, thereby inhibiting

304 the recruitment of mammalian target of rapamycin complex 1 (mTORC1) to lysosomes

305 (Schweitzer et al, 2015). As the levels of the subunit proteins of LAMTOR were also decreased in the Lrrk2 KO LBs (Figure 3C), BORCS6 together with LAMTOR may play a role in the regulation of the size of LBs in AT2 cells.

In summary, we found that BORCS6 is involved in the maintenance of LBs, which we propose to be regulated by LRRK2 (Figure 8). Further studies investigating the molecular mechanism(s) of how LRRK2 regulates the association/dissociation of BORCS6 to/from LBs, as well as how the LRRK2-BORCS6 pathway regulates LB exocytosis in AT2 cells will provide clues towards elucidating the physiological functions of LRRK2. 


\section{Materials and methods}

\section{Animal experiments}

All experiments using animals in this study were performed according to the guidelines provided by the Institutional Animal Care Committee of the Graduate School of Pharmaceutical Sciences at the University of Tokyo (protocol no. P29-48). All animals were maintained on a $12 \mathrm{~h} \mathrm{light/dark}$ cycle with food and water available ad libitum. Lrrk2 KO mice were kindly provided by Professor Jie Shen (Harvard Medical School).

PCR genotyping of Lrrk2 KO mice using genomic DNA extracted from mouse tissues

$$
\text { performed }
$$

using

the

following

three primers: 5 '-

GGCTCTGAAGAAGTTGATAGTCAGGCTG-3',

GAACTTCTGTCTGCAGCCATCATC-3',

and

5'-

CTGTACACTGGCAACTCTCATGTAGGAG-3’.

\section{Quantification of surfactant protein C in BALF}

BALF was collected from terminally anesthetized mice by instilling and retracting

$1 \mathrm{~mL}$ of phosphate-buffered saline (PBS) via a catheter inserted into the trachea. The collected fluid was centrifuged at $500 \mathrm{~g}$ for $10 \mathrm{~min}$ at $4{ }^{\circ} \mathrm{C}$. The supernatant was used for ELISA and protein assay. The ELISA reaction was performed according to the manufacturer's instructions. An Sftpc ELISA kit for the mouse was purchased from Aviva Systems Biology (OKEH01170). Total protein concentration in BALF was determined using a Micro Bicinchoninic Acid Protein Assay kit (G-Biosciences; \#786-572).

The lungs perfused with PBS were dissected, transferred to the homogenization 
340 (Sigma-Aldrich), 10 times the volume of the lung wet weight) and homogenized using a Polytron homogenizer (Hitachi) 2 times each for $10 \mathrm{sec}$ on ice. The homogenates were filtered through a $100 \mu \mathrm{m}$ cell strainer (Falcon), centrifuged at $1,000 \mathrm{~g}$ for $10 \mathrm{~min}$ at $4{ }^{\circ} \mathrm{C}$ to remove cell debris and nuclei, and the supernatants were collected. Sucrose gradient centrifugation was performed using a discontinuous gradient of $0.9 \mathrm{M}$ to $0.2 \mathrm{M}$ sucrose. The post-nuclear supernatants were ultracentrifuged using SW41Ti rotor at 100,000 g for $3 \mathrm{~h}$ at $4{ }^{\circ} \mathrm{C}$ on Optima L-90K (Beckman Coulter). The fraction between 0.4-0.5 M sucrose was collected, and the sucrose concentration was adjusted to $0.24 \mathrm{M}$ using a refractometer. The samples were then ultracentrifuged one more time at $20,000 \mathrm{~g}, 15 \mathrm{~min}$ at $4{ }^{\circ} \mathrm{C}$ to collect the LBs as pellets. For immunoblotting, the pellets containing LBs were solubilized in the SDS-PAGE sample buffer, and the protein concentration of the samples was measured by Micro Bicinchoninic Acid Protein Assay kit (G-Biosciences; \#786-572). 2-mercaptoethanol was added to a final concentration of $1 \%(\mathrm{v} / \mathrm{v})$, and the samples were heated for $15 \mathrm{~min}$ at $37^{\circ} \mathrm{C}$. were resuspended in $50 \mu \mathrm{L}$ per mouse of the lysis buffer $(50 \mathrm{mM}$ Tris- $\mathrm{HCl} \mathrm{pH} 8.0,9 \mathrm{M}$ urea). The suspensions were sonicated 5 times each for $10 \mathrm{sec}$ on ice, and LB lysates were obtained as supernatants following centrifugation. The lysates were snap-frozen in liquid nitrogen and subjected to an LC-MS/MS analysis (Medical ProteoScope, Inc., Japan).

Ten $\mu \mathrm{L}$ of the supernatants were subjected to SDS-PAGE, and the gel was stained with SYPRO Ruby Protein Gel Stain (Thermo Fisher Scientific). Fluorescent images 
were obtained on an image analyzer LAS-3000 (Fujifilm, Japan). The total protein content of each LB fraction was calculated based on the fluorescence intensity using a known amount of HeLa cell lysate running side-by-side as a standard.

Three hundred $\mu \mathrm{g}$ of the LB lysates were dried and solubilized in a solution containing $8 \mathrm{M}$ urea, $50 \mathrm{mM}$ Tris- $\mathrm{HCl}, \mathrm{pH}$ 8.0. The cysteine residues were reduced with dithiothreitol at $37^{\circ} \mathrm{C}$ for $30 \mathrm{~min}$, followed by alkylation with iodoacetamide. The urea concentration of the sample was adjusted to $2 \mathrm{M}$ using a buffer containing $50 \mathrm{mM}$ Tris$\mathrm{HCl} \mathrm{pH} \mathrm{8.0,} \mathrm{and} \mathrm{mass} \mathrm{grade} \mathrm{trypsin} \mathrm{was} \mathrm{added} \mathrm{to} \mathrm{the} \mathrm{samples} \mathrm{and} \mathrm{incubated} \mathrm{at} 37{ }^{\circ} \mathrm{C}$ for 16 h. Digested peptides were desalted using C18 STAGE tips (Rappsilber et al, 2003) and dried under reduced pressure.

The dried peptide samples were dissolved in a solvent (water: acetonitrile: trifluoroacetic acid $=98: 2: 0.1$ by volume). The two-thirds of the samples were purified on a nano HPLC capillary column (particle size: $3 \mu \mathrm{m}$; inner diameter: $75 \mu \mathrm{m}$; length 15 cm) (Nikkyo Technos Co., Ltd., Japan), at a constant flow rate of $350 \mathrm{~nL} / \mathrm{min}$, with a gradient $0 \%$ to $40 \%$ B in 120 min; solvent A: water/formic acid 100:0.1 (v:v); solvent B: water/acetonitrile/formic acid 10:90:0.1 (v:v:v). The MS analysis was performed on a

379 Exactive Orbitrap mass spectrometer (Thermo Fisher Scientific) with the top 10 acquisition method: MS resolution 70,000, between 300 and $1500 \mathrm{~m} / \mathrm{z}$, followed by MS/MS (resolution 17,500) on the most intense 10 peaks. the Mouse UniProt FASTA database (downloaded in December 2018). Enzyme specificity was set to trypsin, and the search included cysteine carbamidomethylation as 
387 modifications. Up to 2 missed cleavages were allowed for protease digestion.

388 Quantification was performed by MaxQuant with 'match between runs' enabled 389 (matching time window: $0.7 \mathrm{~min}$ ).

\section{Bioinformatic analysis on lamellar body proteomes}

Bioinformatic analysis for creating the volcano plot shown in Figure 2E was performed on Perseus and data was visualized using Prism (GraphPad Software). The heatmap shown in Figure 2F created and visualized on R, LFQ intensity values calculated using MaxQuant were converted to z-scores by the genefilter package. The heatmap.s function of the gplot package was used to create heatmaps. Gene ontology enrichment analyses were performed using DAVID (https://david.ncifcrf.gov).

\section{Cell culture}

A549 cells (purchased from JCRB cell bank, Japan (JCRB0076)) and Lenti-X 293 T cells (Takara Bio, Japan) were cultured in high-glucose Dulbecco's modified Eagle's media (DMEM; Fujifilm Wako, Japan; \#044-29765) supplemented with 10\% (v/v) fetal bovine serum (FBS) (Biosera) and 50 units $/ \mathrm{mL}$ penicillin and $50 \mu \mathrm{g} / \mathrm{mL}$ streptomycin at

$37{ }^{\circ} \mathrm{C}$ in a $5 \% \mathrm{CO}_{2}$ atmosphere. If necessary, cells were treated with GSK2578215A

(MedChemExpress), MLi-2 (a kind gift from Professor Dario Alessi (University of 
411 (Takara Bio, Japan) and inserted into pCR4-TOPO (Invitrogen) by TOPO-TA cloning.

412 The hBORCS6 sequence was amplified by PCR using the following oligonucleotides as primers: 5'-CCTCGGTCTCGATTCTACGGGATCCATGGAGTCGTCT-3'， and 5'GAGCTCTAGGATATCGAATTCTCGAGTCACTTGCACAGGGCCTCCAACACC-3’ and inserted into the pLVSIN vector (Takara Bio, Japan) by HiFi assembly (New England Biolabs) according to manufacturer's instructions.

\section{Lentiviral transduction of A549 cells}

A549 cells were plated on 6-well-plate at $5 \times 10^{5}$ cells/well and infected with lentivirus encoding V5-BORCS6. After $24 \mathrm{~h}$ incubation, the medium was replaced with a fresh medium. $24 \mathrm{~h}$ later, the cells were transferred into a $10 \mathrm{~cm}$ dish and cultured with medium containing puromycin at $2 \mu \mathrm{g} / \mathrm{mL}$. Polyclonal cells obtained after passaging several times were used for rescue experiments shown in Figure 7.

\section{Generation of CRISPR knockout cells}

A549 cells were seeded in 6 -well plates at $2 \times 10^{5}$ cells/well and transfected with a set of plasmids targeting a gene (Table S2) using Lipofectamine LTX (Thermo Fisher Scientific) according to the manufacturer's instructions. At $48 \mathrm{~h}$ after transfection, the media were replaced with fresh ones containing puromycin at $2 \mu \mathrm{g} / \mathrm{mL}$. The media was replaced again at $24 \mathrm{~h}$ selection with puromycin. The media were changed to fresh ones not containing puromycin at $48 \mathrm{~h}$ selection, and the cells were grown to confluence. For of 0.4 cells/well into 96-well plates coated with $0.1 \%$ (w/v) gelatin (Fujifilm Wako, Japan; \#190-15805) and cultured in DMEM containing 30\% (v/v) FBS. After reaching 
approximately $80 \%$ confluency, individual clones were transferred to 6-well plates and were sequenced to confirm the knockout: cells were resuspended in QuickExtract (Lucigen), incubated at $65^{\circ} \mathrm{C}$ for $15 \mathrm{~min}$, vortexed for $15 \mathrm{sec}$, and incubated at $98^{\circ} \mathrm{C}$ for $10 \mathrm{~min}$. Cell lysates were then centrifuged at $24,400 \mathrm{~g}$ for $1 \mathrm{~min}$ at $20^{\circ} \mathrm{C}$. Supernatants were collected and PCR was performed using KAPA HiFi HotStart ReadyMix (Roche) to amplify the targeted genomic region. The primers used were listed in Table S3. PCR products were inserted into p3 $\times$ FLAG-CMV-10 vector (Sigma-Aldrich) by HiFi assembly (New England Biolabs) and transformed into DH5 $\alpha$. Plasmids were isolated from 20 clones using a miniprep kit (Nippon Genetics, Japan) and sequenced to confirm frameshift mutations.

\section{Immunoblotting}

Immunoblotting was performed as described previously (Ito \& Tomita, 2017).

Immunocytochemical experiments

Cells were cultured on glass coverslips. The cells were washed with DPBS and fixed with $4 \%(\mathrm{w} / \mathrm{v})$ paraformaldehyde/PBS for $15 \mathrm{~min}$ at room temperature. The fixed cells were washed with PBS 3 times and permeabilized in $0.1 \%(\mathrm{v} / \mathrm{v})$ Triton-X 100/PBS for 30 antibodies diluted in the blocking buffer overnight at $4^{\circ} \mathrm{C}$. After washing with PBS, 
temperature. The samples were then extensively washed with PBS and mounted using

ProLong Diamond (Thermo Fisher Scientific). Images were taken on a confocal

microscope (SP5, Leica). Image contrast and brightness were adjusted using ImageJ.

Antibodies used for immunoblotting were listed in Table S1.

\section{Transmission electron microscopy (TEM)}

After perfusion of the lung with DPBS, a catheter was inserted into the trachea to

wash inside the lung and apply a fixative solution (2\% paraformaldehyde, $2.5 \%$

glutaraldehyde in phosphate buffer). The lung was removed and incubated in the fixative

solution at room temperature with gentle agitation. After $24 \mathrm{~h}$ fixation, the lung was

chopped into $1-\mathrm{mm}^{3}$ blocks and processed as described below.

A549 cells were seeded in 6 -well plates at $6 \times 10^{5}$ cells/well. After $24 \mathrm{~h}$, the cells

were washed with DPBS, detached with trypsin/EDTA, and collected into $1.5 \mathrm{~mL}$ tubes.

Cells were centrifuged at $1,500 \mathrm{~g}$ for $5 \mathrm{~min}$ at $4{ }^{\circ} \mathrm{C}$ and the supernatants were discarded.

The cell pellets were washed with DPBS, resuspended in $1 \mathrm{~mL}$ of the fixative solution, and incubated for $1 \mathrm{~h}$ at room temperature. The cells were then pelleted and washed 3 times with PBS. Five hundred microliters of $4 \%(\mathrm{w} / \mathrm{v})$ low-melting temperature agarose (Sigma-Aldrich) diluted in double deionized water (DDW) were added to the tubes without collapsing the pellet, and the samples were left to stand at room temperature for $10 \mathrm{~min}$ and then on ice for $20 \mathrm{~min}$ to harden the agarose. The pellets embedded in agarose were chopped into $1-\mathrm{mm}^{3}$ blocks on ice and immersed in $0.1 \mathrm{M}$ cacodylate- $\mathrm{HCl} \mathrm{pH} 7.4$ repeated 3 times. The blocks were post-fixed with 1\%(w/v) $\mathrm{OsO}_{4}$ (Nisshin EM, Japan), 
blocks were then washed with DDW 2 times for $10 \mathrm{~min}$ and incubated in $1 \%(\mathrm{w} / \mathrm{v})$ uranyl acetate (Merck)/70\% (v/v) ethanol for $40 \mathrm{~min}$ at room temperature in the dark. The blocks were rinsed with $70 \%$ ethanol and washed with $80 \%, 90 \%, 95 \%, 99 \%$ (once for each), and $100 \%$ ethanol for 2 times at room temperature each for $10 \mathrm{~min}$. The blocks were dehydrated twice with QY-1 (Nisshin EM) for 10 min at room temperature, put in the 1:1 mixture of Durcupan (Sigma-Aldrich) and QY-1, and rotated overnight at room temperature. On the next day, the samples were transferred to Durcupan and rotated for 2 $\mathrm{h}$ at room temperature. This process was repeated 2 more times. Fresh Durcupan was poured into molds, where the samples were immersed, and the samples were hardened at $60{ }^{\circ} \mathrm{C}$ for $48 \mathrm{~h}$. Seventy nanometers-thick ultrathin sections were prepared with an ultramicrotome, picked up onto a mesh (Okenshoji, Japan) covered with Formvar, stained with $4 \%(\mathrm{w} / \mathrm{v})$ uranyl acetate for $5 \mathrm{~min}$ in the dark under a humid condition. After an extensive wash with DDW, the sections were treated with Reynolds solution in the performed on ImageJ with the person quantifying kept blind to the sample identity.

\section{$\underline{\text { Statistical analysis }}$}

Statistical significance of the difference between two samples and among multiple samples was calculated by the Student's t-test and Tukey-Kramer's test, respectively, on 


\section{Acknowledgements}

We are grateful to Drs. Dario Alessi (University of Dundee, UK) and Jie Shen (Harvard Medical School, USA) for providing MLi-2 and Lrrk2 knockout mice, respectively. We thank our current and past laboratory members for helpful discussions. Social Cooperation Program of Brain and Neurological Disorders at the Graduate School of Pharmaceutical Sciences, The University of Tokyo is supported by Biogen. This work was supported in part by Biogen; the Grants-in-Aid for Scientific Research (A) [grant number 15H02492/ 19H01015 (to T.T.)]; the Grants-in-Aid for Scientific Research (C) [grant number 17K08265 (to G.I.)]; the Challenging Exploratory Research [grant number 16K15229 (to T.T.)] from the Japan Society for the Promotion of Science; GSK Japan Research Grant 2017 (to G.I.); and the Mitsubishi Foundation (to T.T.).

\section{Author contributions}

MA planned and performed experiments and analyses in all figures, discussed results, and wrote the manuscript. ST was instrumental in experiments involving electron microscopy, and discussed results. GI and TT planned experiments, discussed results, and wrote the manuscript. All authors revised the manuscript.

\section{Conflict of interest}

The authors declare that they have no conflict of interest. 


\section{References}

Andersen MA, Wegener KM, Larsen S, Badolo L, Smith GP, Jeggo R, Jensen PH, Sotty F, Christensen KV \& Thougaard A (2018) PFE-360-induced LRRK2 inhibition induces reversible, non-adverse renal changes in rats. Toxicology 395: 15-22

Araki M, Ito G \& Tomita T (2018) Physiological and pathological functions of LRRK2: implications from substrate proteins. Neuronal Signal 2: NS20180005

Civiero L, Vancraenenbroeck R, Belluzzi E, Beilina A, Lobbestael E, Reyniers L, Gao F, Micetic I, De Maeyer M, Bubacco L, et al (2012) Biochemical characterization of highly purified leucine-rich repeat kinases 1 and 2 demonstrates formation of homodimers. PLoS One 7: e43472

Cox J \& Mann M (2008) MaxQuant enables high peptide identification rates, individualized p.p.b.-range mass accuracies and proteome-wide protein quantification. Nat Biotechnol 26: 1367-72

Eguchi T, Kuwahara T, Sakurai M, Komori T, Fujimoto T, Ito G, Yoshimura S, Harada A, Fukuda M, Koike M, et al (2018) LRRK2 and its substrate Rab GTPases are sequentially targeted onto stressed lysosomes and maintain their homeostasis. Proc Natl Acad Sci 115: E9115-E9124

Encarnação M, Espada L, Escrevente C, Mateus D, Ramalho J, Michelet X, Santarino I, Hsu VW, Brenner MB, Barral DC, et al (2016) A Rab3a-dependent complex essential for lysosome positioning and plasma membrane repair. J Cell Biol 213: $631-640$

Filipek PA, de Araujo MEG, Vogel GF, De Smet CH, Eberharter D, Rebsamen M, Rudashevskaya EL, Kremser L, Yordanov T, Tschaikner P, et al (2017) LAMTOR/Ragulator is a negative regulator of Arl8b- and BORC-dependent late 
endosomal positioning. J Cell Biol 216: 4199-4215

552

Fuji RN, Flagella M, Baca M, Baptista MAS, Brodbeck J, Chan BK, Fiske BK, Honigberg L, Jubb AM, Katavolos P, et al (2015) Effect of selective LRRK2 kinase inhibition on nonhuman primate lung. Sci Transl Med 7: 1-13

Giasson BI, Covy JP, Bonini NM, Hurtig HI, Farrer MJ, Trojanowski JQ \& Van Deerlin VM (2006) Biochemical and pathological characterization of Lrrk2. Ann Neurol 59: $315-22$

Guardia CM, Farías GG, Jia R, Pu J \& Bonifacino JS (2016) BORC Functions Upstream of Kinesins 1 and 3 to Coordinate Regional Movement of Lysosomes along Different Microtubule Tracks. Cell Rep 17: 1950-1961

Harney J, Bajaj P, Finley JE, Kopec AK, Koza-Taylor PH, Boucher GG, Lanz TA, Doshna CM, Somps CJ, Adkins K, et al (2020) An in vitro alveolar epithelial cell model recapitulates LRRK2 inhibitor-induced increases in lamellar body size observed in preclinical models. Toxicol Vitr: 105012

Herzig MC, Kolly C, Persohn E, Theil D, Schweizer T, Hafner T, Stemmelen C, Troxler TJ, Schmid P, Danner S, et al (2011) LRRK2 protein levels are determined by kinase function and are crucial for kidney and lung homeostasis in mice. Hum Mol Genet 20: 4209-23

Hook GER \& Gilmore LB (1982) Hydrolases of pulmonary lysosomes and lamellar bodies. J Biol Chem 257: 9211-9220

Ito G, Katsemonova K, Tonelli F, Lis P, Baptista M, Shpiro N, Duddy G, Wilson S, Ho W-L, Ho S-L, et al (2016) Phos-tag analysis of Rab10 phosphorylation by LRRK2: a powerful assay for assessing kinase function and inhibitors. Biochem J 473: $2671-2685$ 
Ito G \& Tomita T (2017) Rab10 Phosphorylation Detection by LRRK2 Activity Using SDS-PAGE with a Phosphate-binding Tag. J Vis Exp: 1-9

Mason RJ \& Williams MC (1980) Phospholipid composition and ultrastructure of A549 cells and other cultured pulmonary epithelial cells of presumed type II cell origin. Biochim Biophys Acta (BBA)/Lipids Lipid Metab 617: 36-50

Miklavc P, Ehinger K \& Thompson K (2014) Surfactant Secretion in LRRK2 KnockOut Rats: Changes in Lamellar Body Morphology and Rate of Exocytosis. PLoS One 9

Mills RD, Mulhern TD, Cheng H-C \& Culvenor JG (2012) Analysis of LRRK2 accessory repeat domains: prediction of repeat length, number and sites of Parkinson's disease mutations. Biochem Soc Trans 40: 1086-9

Osanai K, Higuchi J, Oikawa R, Kobayashi M, Tsuchihara K, Iguchi M, Huang J, Voelker DR \& Toga H (2010) Altered lung surfactant system in a Rab38-deficient rat model of Hermansky-Pudlak syndrome. Am J Physiol Cell Mol Physiol 298: L243-L251

Paisán-Ruíz C, Jain S, Evans EW, Gilks WP, Simón J, van der Brug M, López de Munain A, Aparicio S, Gil AM, Khan N, et al (2004) Cloning of the gene containing mutations that cause PARK8-linked Parkinson's disease. Neuron 44: $595-600$

Pu J, Schindler C, Jia R, Jarnik M, Backlund P \& Bonifacino JS (2015) BORC, a Multisubunit Complex that Regulates Lysosome Positioning. Dev Cell 33: 176188

Rappsilber J, Ishihama Y \& Mann M (2003) Stop And Go Extraction tips for matrixassisted laser desorption/ionization, nanoelectrospray, and LC/MS sample 
Ridsdale R, Na C-L, Xu Y, Greis KD \& Weaver TE (2011) Comparative Proteomic Analysis of Lung Lamellar Bodies and Lysosome-Related Organelles. PLoS One 6: e16482

Satake W, Nakabayashi Y, Mizuta I, Hirota Y, Ito C, Kubo M, Kawaguchi T, Tsunoda T, Watanabe M, Takeda A, et al (2009) Genome-wide association study identifies common variants at four loci as genetic risk factors for Parkinson's disease. Nat Genet 41: 1303-1307

Schweitzer LD, Comb WC, Bar-Peled L \& Sabatini DM (2015) Disruption of the RagRagulator Complex by c17orf59 Inhibits mTORC1. Cell Rep 12: 1445-1455

Simón-Sánchez J, Schulte C, Bras JM, Sharma M, Gibbs JR, Berg D, Paisán-Ruíz C, Lichtner P, Scholz SW, Hernandez DG, et al (2009) Genome-wide association study reveals genetic risk underlying Parkinson's disease. Nat Genet 41: 13081312

Steger M, Diez F, Dhekne HS, Lis P, Nirujogi RS, Karayel O, Tonelli F, Martinez TN,

Steger M, Tonelli F, Ito G, Davies P, Trost M, Vetter M, Wachter S, Lorentzen E, Duddy G, Wilson S, et al (2016) Phosphoproteomics reveals that Parkinson's disease kinase LRRK2 regulates a subset of Rab GTPases. Elife 5: e12813 139: 318-324 doi:10.1111/jnc.13691 [PREPRINT] 

and structural characterization of the leucine rich repeat namesake domain of leucine rich repeat kinase 2. Biochim Biophys Acta 1824: 450-60

Wadsworth SJ, Spitzer AR \& Chander A (1997) Ionic regulation of proton chemical $(\mathrm{pH})$ and electrical gradients in lung lamellar bodies. Am J Physiol - Lung Cell Mol Physiol 273

Weaver TE, Na C-L \& Stahlman M (2002) Biogenesis of lamellar bodies, lysosomerelated organelles involved in storage and secretion of pulmonary surfactant. Semin Cell Dev Biol 13: 263-270

Van Weeren L, De Graaff AM, Jamieson JD, Batenburg JJ \& Valentijn JA (2004) phosphorylation promotes lipid storage. Lipids Health Dis 17: 34 
$644 \quad$ Figure 1. Lrrk2 knockout mice exhibited enlarged lamellar bodies in the lung.

645 A) Representative images of LBs (asterisks in the bottom panels) in WT, Lrrk2 +/646 (HET), and Lrrk2 KO mouse lungs (male, 2 months old) observed by TEM. Regions 647 marked with white dotted lines in the top panels were magnified in the bottom panels. $648 \quad$ Scale bars: $500 \mathrm{~nm}$ (top/bottom panels).

649 B) The areas of LBs in the TEM images were manually measured on ImageJ and their 650 probability distributions were presented as violin plots. The circles in the plot represent the medians of the values. The total numbers of LBs examined were 382 (WT), 431 (Lrrk2 HET) and 442 (Lrrk2 KO). ***p<0.001 (Kolmogorov-Smirnov

C) The concentrations of Sftpc in BALF collected from WT and Lrrk2 KO mice were measured by ELISA ( $n=6$, male, 3 months old for both genotypes). The values were normalized by the amount of total proteins in the BALF. The circles in the graph represent individual values. The bars and the error bars in the graph represent the

Figure 2. Lamellar body proteome was substantially changed in Lrrk2 KO mice. mean values and the standard errors, respectively. ${ }^{* *} \mathrm{p}<0.01$ (Student's t-test).

A) A schematic depiction of LB isolation from a mouse lung by sucrose gradient centrifugation.

B) Fractions obtained by the sucrose gradient centrifugation (fractions 1-11 collected from the bottom), as well as the supernatant $(\mathrm{S})$ and pellet $(\mathrm{P})$ fractions after the second centrifugation was analyzed by immunoblotting with indicated antibodies. Abca3, Atp8a1, and Lamp1 are proteins existing in LBs, whereas Rab5 and Rcas1 
are markers for endosomes and Golgi apparatus, respectively.

C) The percentage of the lung wet weight to the bodyweight of WT and Lrrk2 KO mice ( $\mathrm{n}=4$, male, 3 months old for both genotypes). The dots in the graph represent individual values. The bars and the error bars in the graph represent the mean values and the standard errors, respectively. "n.s." means "not significant" (Student's t-test).

D) The amount of LB proteins measured on an SDS-PAGE gel stained with SYPRO $* * * \mathrm{p}<0.001$ (Student's t-test).

E) A volcano plot of the 1,519 proteins quantified in the LC-MS/MS analysis of the LB fractions. Each circle represents a protein. Significantly increased proteins in the

A-C) Expression levels of the indicated proteins in LB fractions were analyzed by Lrrk2 KO LBs were marked in red, whereas significantly decreased proteins were marked in blue. The proteins picked up in Fig. 3 were marked in yellow circles. The LB proteins analyzed in Fig. 2B were marked in yellow diamonds.

F) A heat map of the quantitative values of the LRRK2-regulated proteins. The genotypes (WT1-3 and KO1-3) were shown at the bottom of the heat map. The zscores were color-coded from -2 (blue) to 2 (red). immunoblotting (left panel). Lamp1 was used as a loading control. Three-month-old male mice were used for both genotypes. The dots in the graph represent individual values. The bars and the error bars in the graph represent the mean values and the standard errors, respectively. $* * * p<0.001$ (Student's t-test). The numbers of mice 
Figure 4. Immunoblot of the regulated proteins in lung homogenates

A-C) Expression levels of the indicated proteins in lung homogenates were analyzed by immunoblotting (left panel). $\alpha$-tubulin was used as a loading control. Lung homogenates were prepared from the identical sets of mice described in Figure 3. The dots in the graph represent individual values. The bars and the error bars in the graph represent the mean values and the standard errors, respectively. "n.s." means "not significant" (Student's t-test). The numbers of mice examined were $4 \mathrm{WT}$ and 4 Lrrk2 KO in (A), 4 WT and 5 Lrrk2 KO in (B), and 6 WT and 6 Lrrk2 KO in (C).

\section{Figure 5. LRRK2 KO caused lamellar body enlargement in A549 cells.}

A) Expression levels of endogenous total LRRK2, phospho-Ser935 LRRK2, endogenous total Rab10, and phospho-Thr73 Rab10 in A549 parental (WT) as well as in LRRK2 KO clones (\#28, \#104, and \#126) were examined by immunoblotting. $\alpha$-tubulin was used as a loading control. Cells were treated with $0.1 \%$ DMSO (-) or $10 \mathrm{nM} \mathrm{MLi}-2(+)$ for $24 \mathrm{~h}$ prior to lysis.

B) Representative images of LBs (asterisks in the bottom panels) in A549 WT as well as $L R R K 2 \mathrm{KO}$ cells observed by TEM at low magnification (top panels; scale bars: 1 $\mu \mathrm{m})$ and high magnification (bottom panels; scale bars: $500 \mathrm{~nm}$ ). Regions marked with white dotted lines in the top panels were magnified in the bottom panels.

C) The areas of LBs in the TEM images were manually measured on ImageJ and their probability distributions were presented as violin plots. The circles in the plot 
represent the medians of the values. The total numbers of LBs examined were 400 test).

D) Expression levels of endogenous total LRRK2 and phospho-Ser935 LRRK2 in A549 WT cells treated with $0.1 \%$ DMSO, $1 \mu \mathrm{M}$ GSK2578215A (GSK), or $10 \mathrm{nM}$ MLi-2 for 1 week were examined by immunoblotting. $\alpha$-tubulin was used as a loading control.

E) Representative images of LBs (asterisks in the bottom panels) in A549 cells treated with DMSO, GSK2578215A, or MLi-2 observed by TEM at low magnification (top panels; scale bars: $1 \mu \mathrm{m}$ ) and high magnification (bottom panels; scale bars: $500 \mathrm{~nm}$ ). Regions marked with white dotted lines in the top panels were magnified in the bottom panels.

F) The areas of LBs in the TEM images were manually measured on ImageJ and their probability distributions were presented as violin plots. The circles in the plot represent the medians of the values. The total numbers of LBs examined were 387 as well as in (A) BORCS5 KO clones (\#10,\#13, \#20), (B) BORCS6 KO clones (\#9, \#11, \#17), or BORCS7 KO clones (\#36, \#39, \#42) were examined by immunoblotting. $\alpha$-tubulin was used as a loading control.

D) Merged immunocytochemical images of A549 WT, BORCS5 KO (\#13), BORCS6 
KO (\#9), BORCS7 KO (\#42) cells stained with an anti-LAMP1 antibody (gray).

Nuclei were stained with DAPI (blue). Scale bars: $10 \mu \mathrm{m}$.

E) Representative images of LBs (asterisks in the bottom panels) in A549 WT, BORCS5 KO (\#13), BORCS6 KO (\#9), BORCS7 KO (\#42) cells observed by TEM at low magnification (top panels; scale bars: $1 \mu \mathrm{m}$ ) and high magnification (bottom panels; scale bars: $500 \mathrm{~nm}$ ). Regions marked with white dotted lines in the top panels were magnified in the bottom panels.

F) The areas of LBs in the TEM images were manually measured on ImageJ and their probability distributions were presented as violin plots. The circles in the plot represent the medians of the values. The total numbers of LBs examined were 426 (WT), 380 (BORCS5 KO \#13), 400 (BORCS6 KO \#9), and 406 (BORCS7 KO \#42).

Figure 7. BORCS6 KO caused lamellar body enlargement in A549 cells.

A) Representative images of LBs (asterisks in the bottom panels) in A549 WT as well as BORCS6 KO cells (clones \#9, \#11, and \#17) observed by TEM at low magnification (top panels; scale bars: $1 \mu \mathrm{m}$ ) and high magnification (bottom panels; scale bars: $500 \mathrm{~nm}$ ). Regions marked with white dotted lines in the top panels were

B) The areas of LBs in the TEM images were manually measured on ImageJ and their probability distributions were presented as violin plots. The circles in the plot represent the medians of the values. The total numbers of LBs examined were 426 (WT), 400 (\#9), 406 (\#11), and 417 (\#17). ${ }^{* * *} \mathrm{p}<0.001$ (Kolmogorov-Smirnov test).

C) Expression levels of endogenous total Rab10, phospho-Thr73 Rab10, total Rab12, 
and phospho-Ser106 Rab12 were examined by immunoblotting. The same sets of samples used in Figure 6B were used.

D) Expression levels of BORCS6 in A549 parental (WT) cells, BORCS6 KO\#11 cells, as well as BORCS6 KO\#11 cells stably expressing V5-BORCS6 were examined by immunoblotting. Note that longer exposure was required to detect exogenously expressed V5-BORCS6 (arrow) by an anti-BORCS6 antibody, where the band corresponding to endogenous BORCS6 (arrowhead) in WT cells became saturated (the second panel from the top). $\alpha$-tubulin was used as a loading control.

E) Representative images of LBs (asterisks in the bottom panels) in A549 parental (WT) cells, BORCS6 KO\#11 cells, as well as V5-BORCS6 cells observed by TEM at low magnification (top panels; scale bars: $1 \mu \mathrm{m}$ ) and high magnification (bottom panels; scale bars: $500 \mathrm{~nm}$ ). Regions marked with white dotted lines in the top panels were magnified in the bottom panels.

F) The areas of LBs in the TEM images were manually measured on ImageJ and their probability distributions were presented as violin plots. The circles in the plot represent the medians of the values. The total numbers of LBs examined were 428 (WT), 432 (\#11), and 421 (\#rescue). ***p<0.001 (Kolmogorov-Smirnov test). 
bioRxiv preprint doi: https:/doi.org/10.1101/2021.03.05.434068; this version posted March 5, 2021. The copyright holder for this preprint (which was not certified by peer review) is the author/funder, who has granted bioRxiv a license to display the preprint in perpetuity. It is made available under aCC-BY-NC-ND 4.0 International license.

785

786

787

788

789

790

791

792

793

794

795

796

797

798

799

800

801

802

803

804

805

806

Figure 1
A

WT
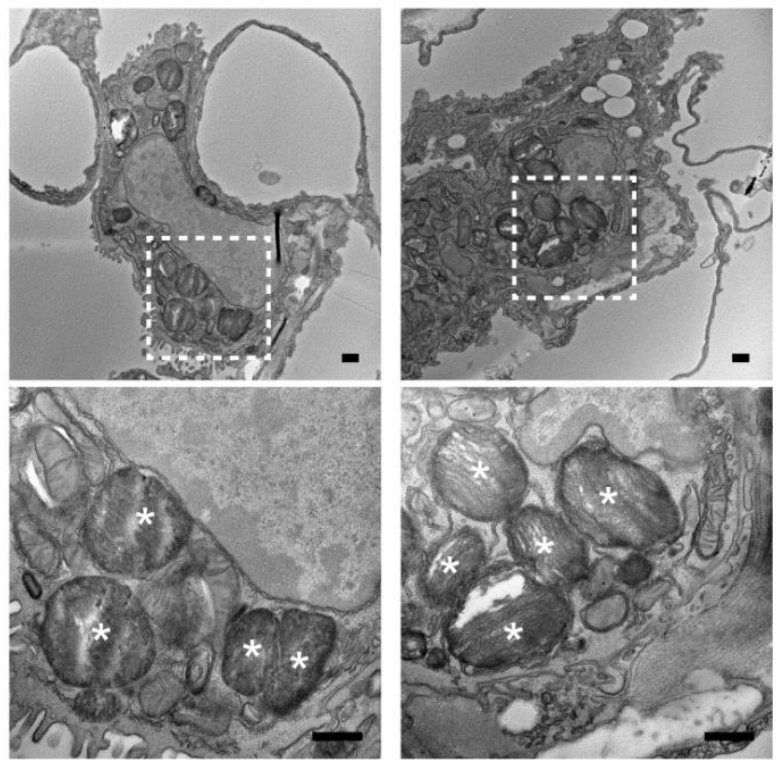

\section{Lrrk2 KO}
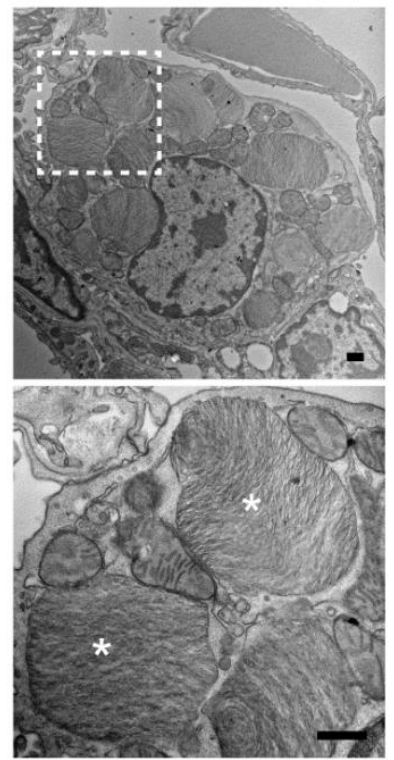

B

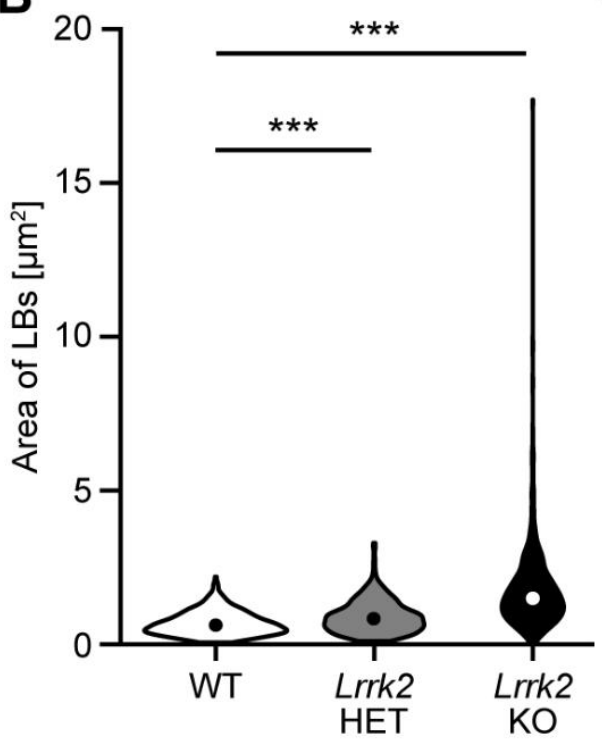

C

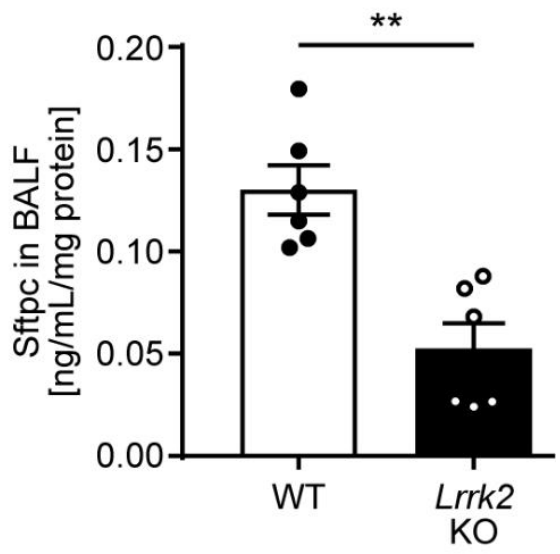


bioRxiv preprint doi: https://doi.org/10.1101/2021.03.05.434068; this version posted March 5, 2021. The copyright holder for this preprint (which was not certified by peer review) is the author/funder, who has granted bioRxiv a license to display the preprint in perpetuity. It is made available under aCC-BY-NC-ND 4.0 International license.

808

A
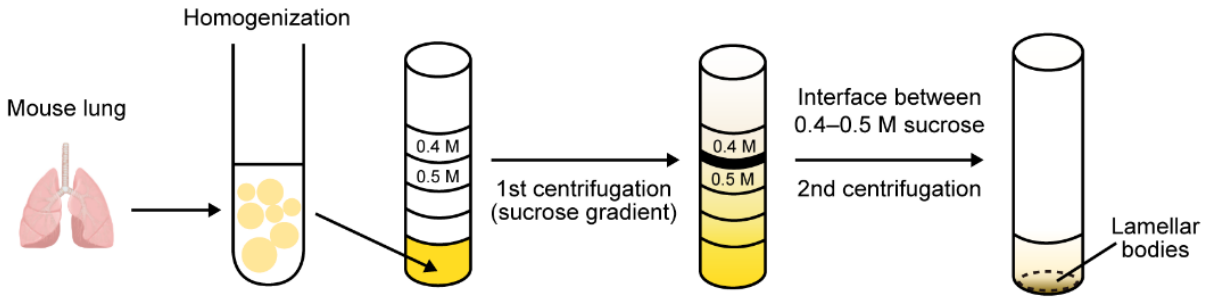

811

B

Sucrose gradient fractions (1st)

2nd

C

812

814

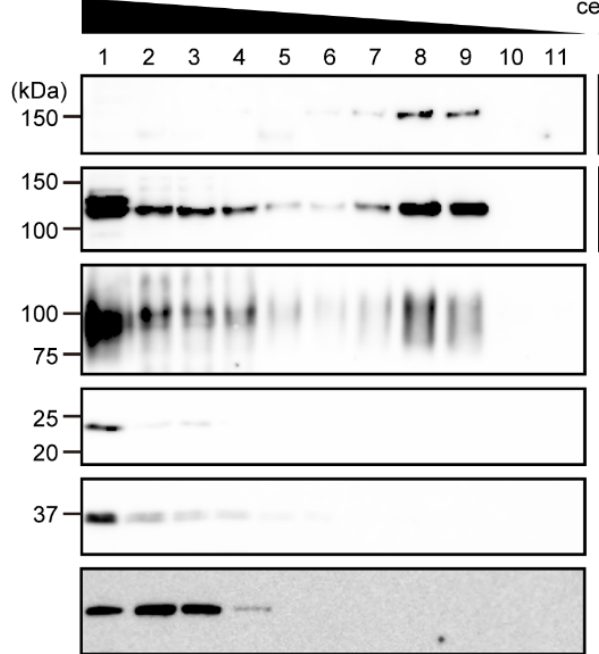

centrifugation

E
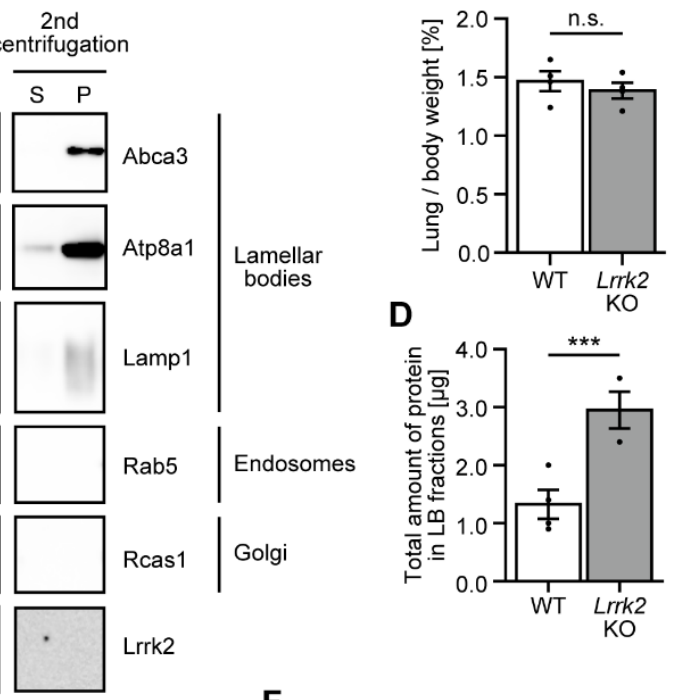

bodies

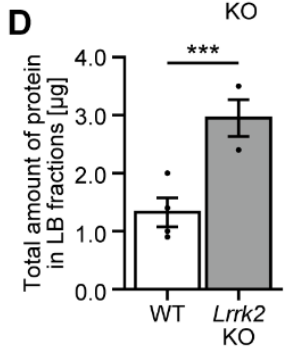

Lrrk2

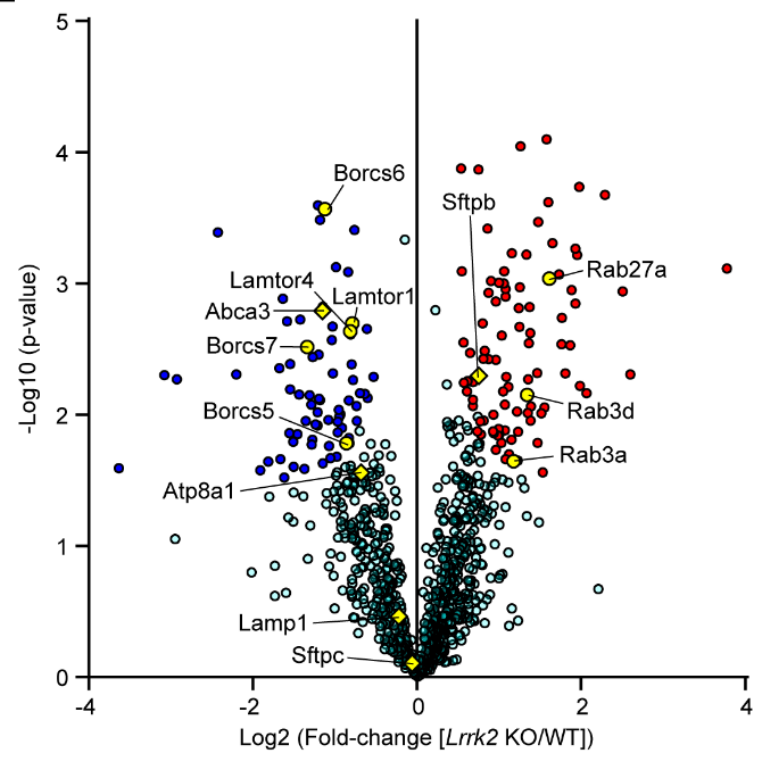

F
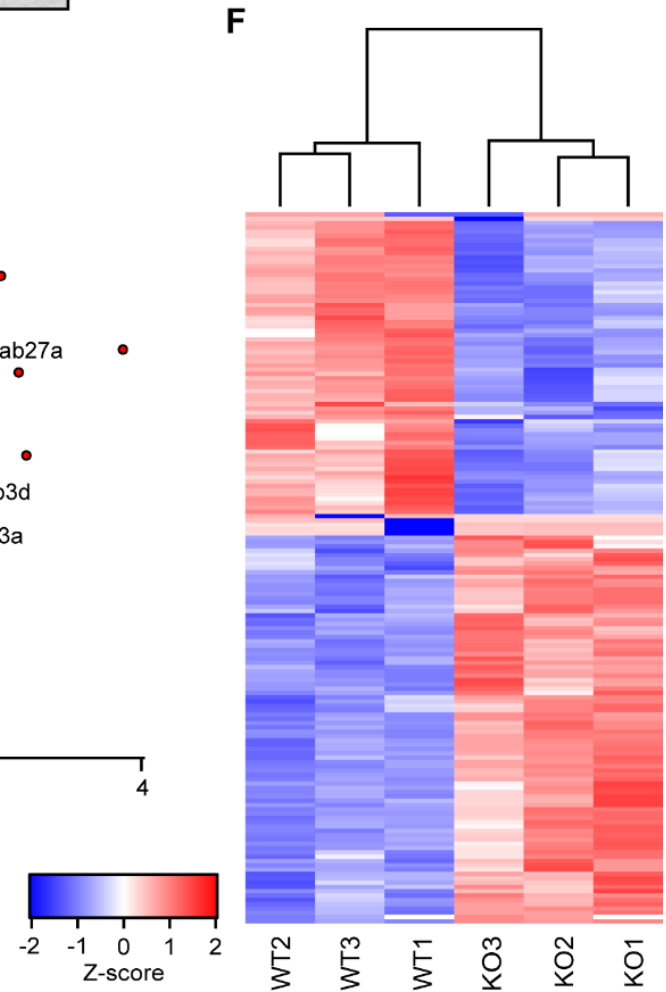

830

Figure 2 
bioRxiv preprint doi: https://doi.org/10.1101/2021.03.05.434068; this version posted March 5, 2021. The copyright holder for this preprint (which was not certified by peer review) is the author/funder, who has granted bioRxiv a license to display the preprint in perpetuity. It is made available under aCC-BY-NC-ND 4.0 International license.

A Lamellar body fractions

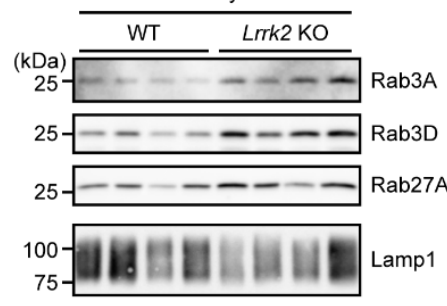

B Lamellar body fractions
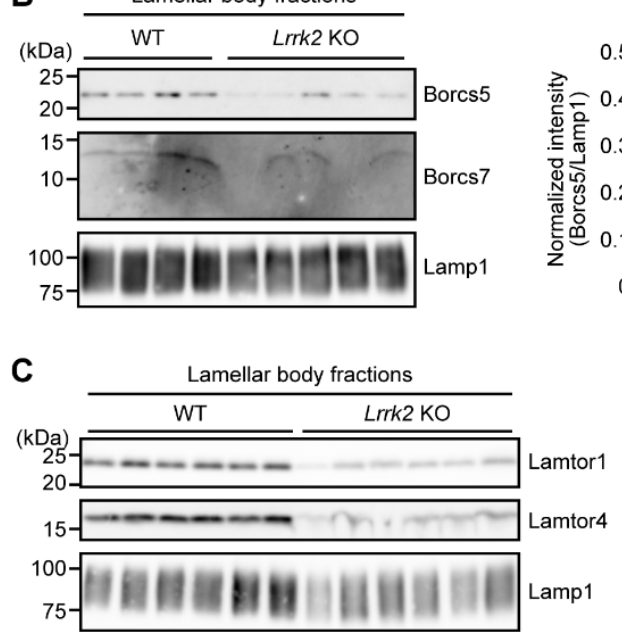
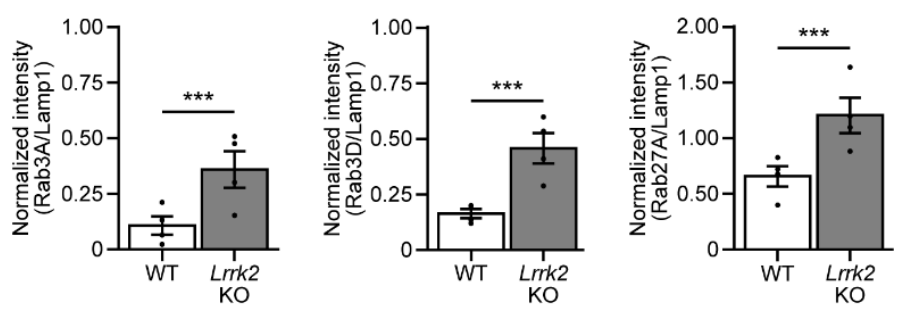
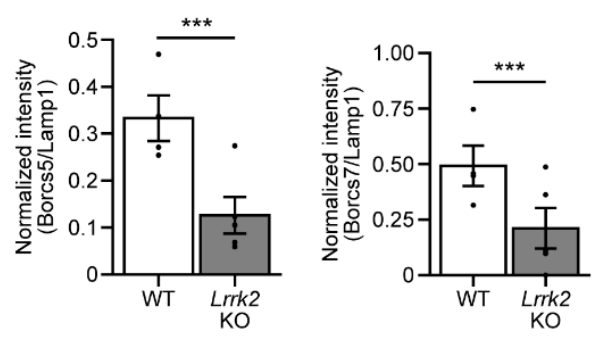
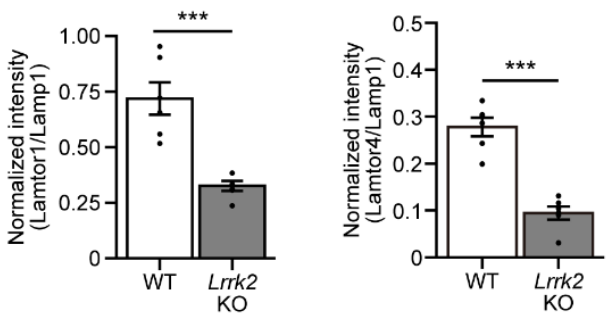

844

Figure 3

846 
bioRxiv preprint doi: https://doi.org/10.1101/2021.03.05.434068; this version posted March 5, 2021. The copyright holder for this preprint (which was not certified by peer review) is the author/funder, who has granted bioRxiv a license to display the preprint in perpetuity. It is made available under aCC-BY-NC-ND 4.0 International license.
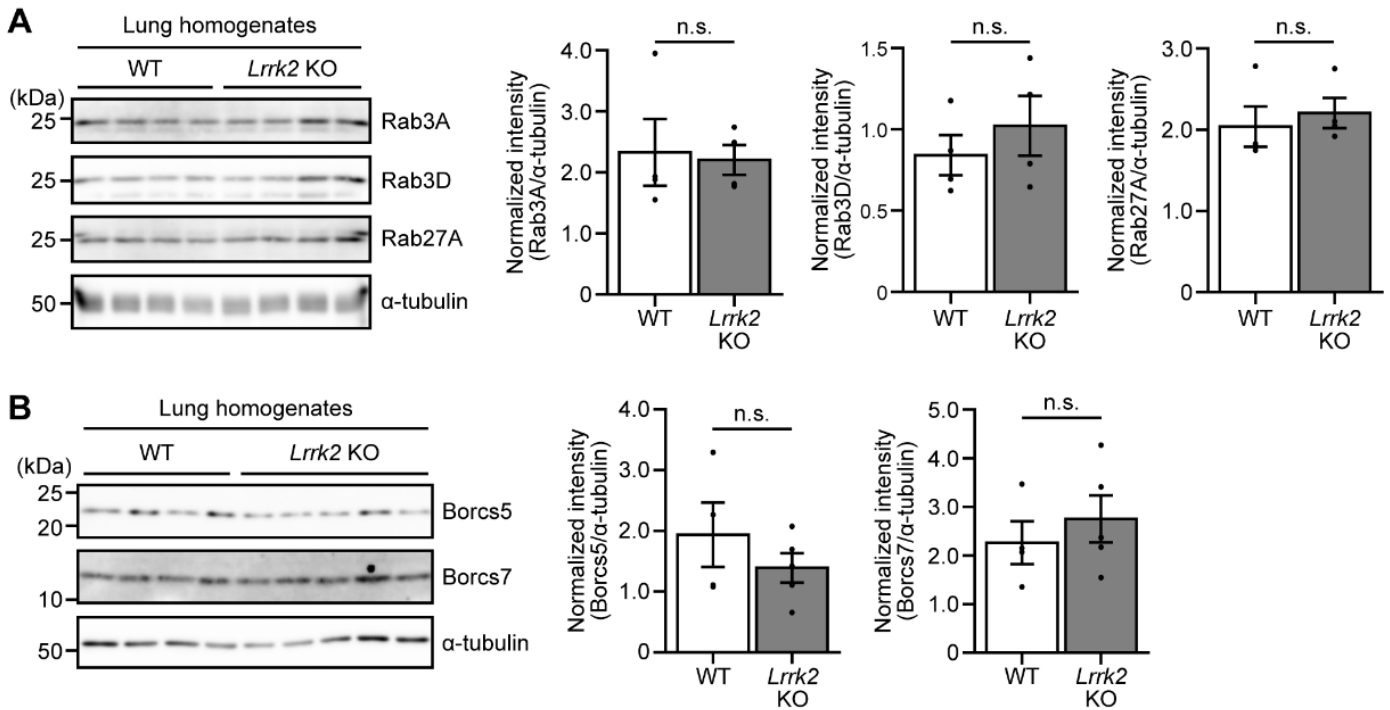

854

C

Lung homogenates
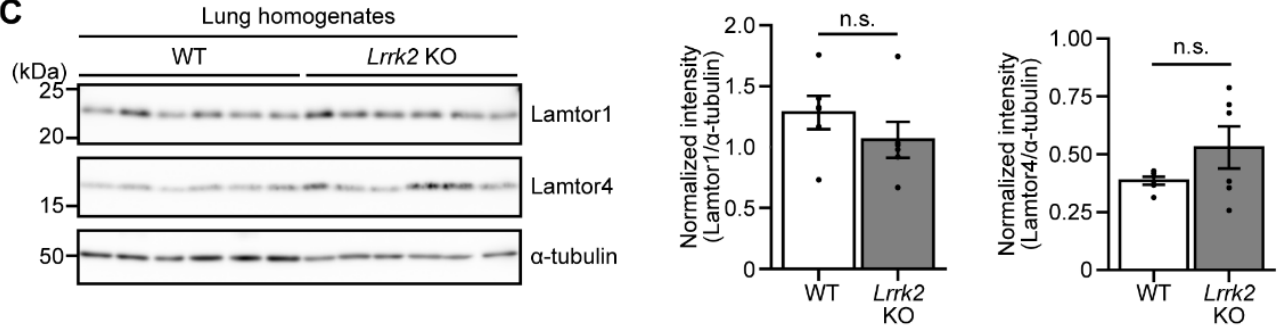

860

Figure 4

861 
bioRxiv preprint doi: https://doi.org/10.1101/2021.03.05.434068; this version posted March 5, 2021. The copyright holder for this preprint (which was not certified by peer review) is the author/funder, who has granted bioRxiv a license to display the preprint in perpetuity. It is made available under aCC-BY-NC-ND 4.0 International license.

862

863

864

865

866

867

868

869

870

871

872

877

878

A

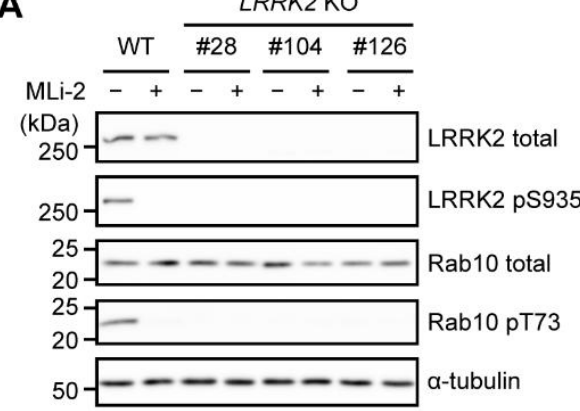

B
D

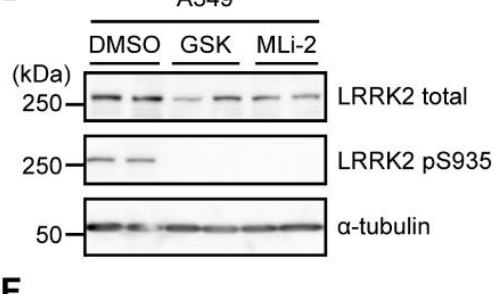

F

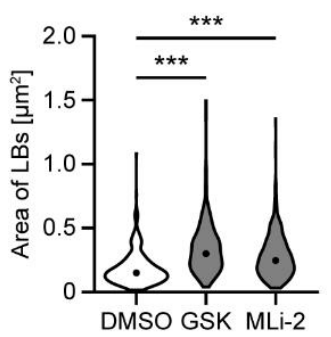

C

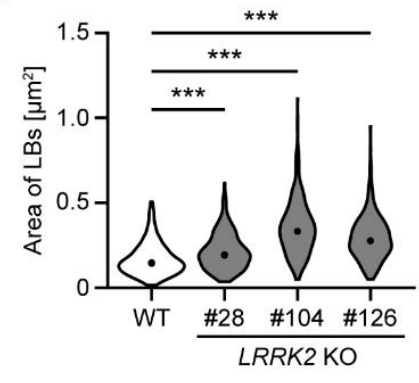

A549 LRRK2 KO

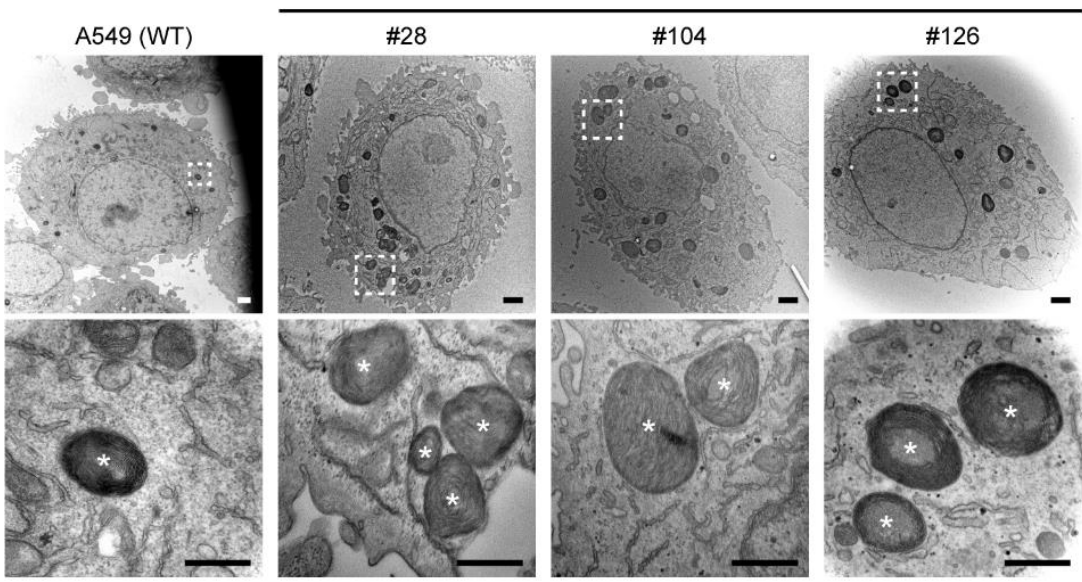

E

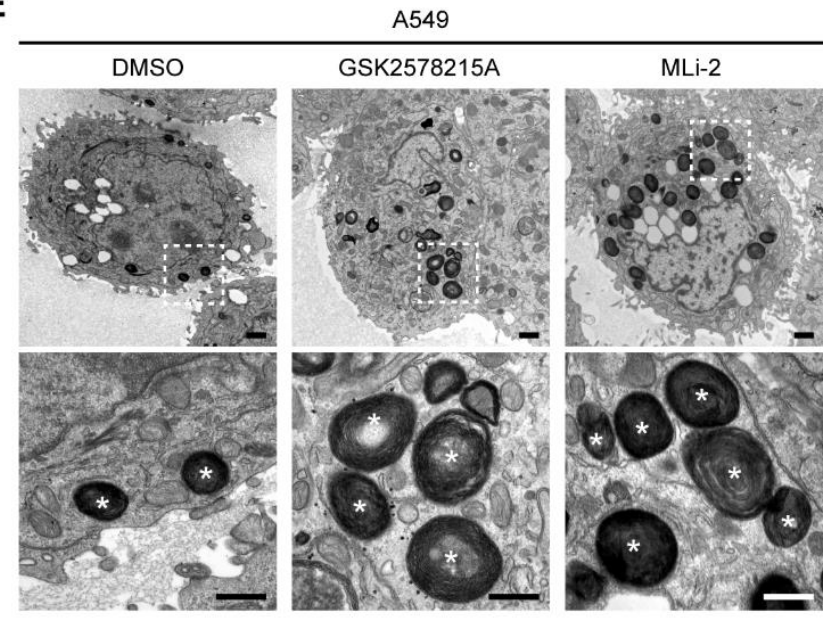

881

882

883

Figure 5 
bioRxiv preprint doi: https://doi.org/10.1101/2021.03.05.434068; this version posted March 5, 2021. The copyright holder for this preprint (which was not certified by peer review) is the author/funder, who has granted bioRxiv a license to display the preprint in perpetuity. It is made available under aCC-BY-NC-ND 4.0 International license.

885

886

887

888

889

890

891

892

894

895

896

897

898

899

900

$901 \quad$ Figure 6

902

D

E

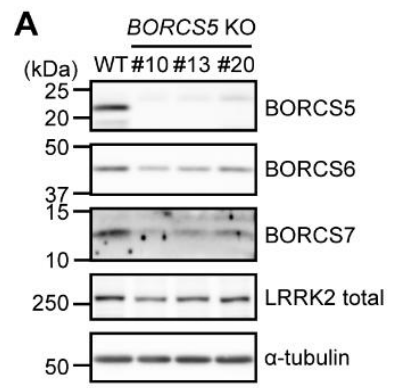

B

(kDa) WT \#9 \#11 \#17

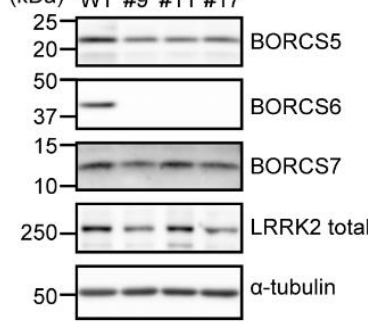

A549 (WT)

A549

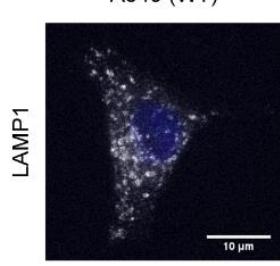

BORCS5 KO \#13

A5 49
BORCS6 KO \#9
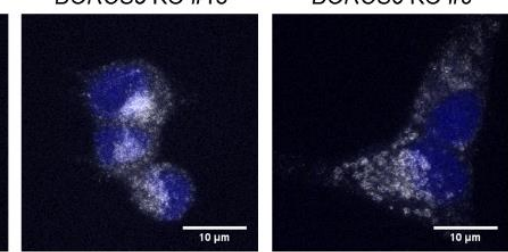

A549 (WT)
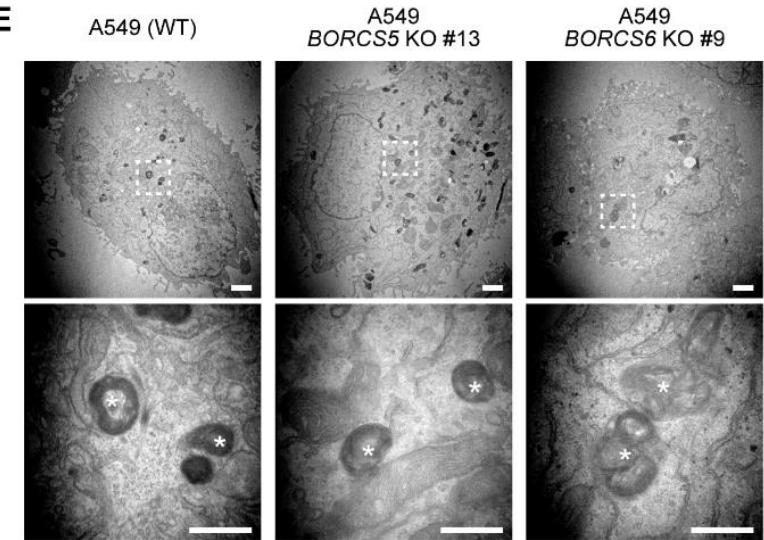

C BORCST KO

(kDa) WT $\overline{\# 36 \# 39 \# 42}$

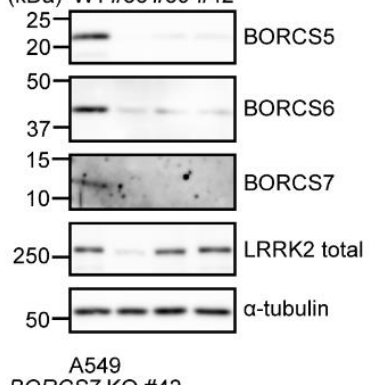

A549
BORCS7 KO \#42

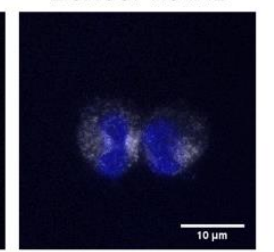

A5 49
BORCS KO \#42

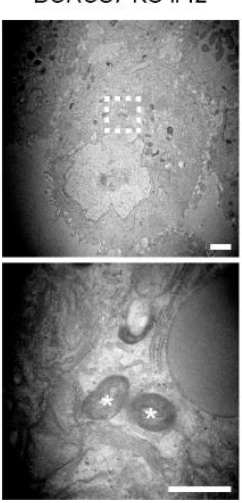

F

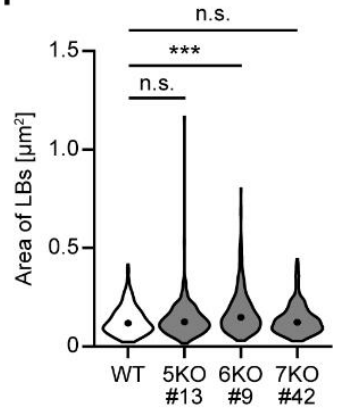


bioRxiv preprint doi: https://doi.org/10.1101/2021.03.05.434068; this version posted March 5, 2021. The copyright holder for this preprint (which was not certified by peer review) is the author/funder, who has granted bioRxiv a license to display the preprint in perpetuity. It is made available under aCC-BY-NC-ND 4.0 International license.

903

A

A549 (WT)

A549

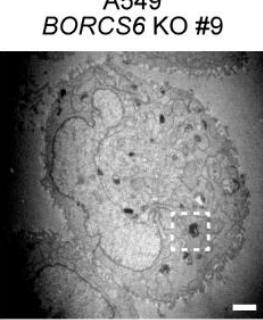

A549

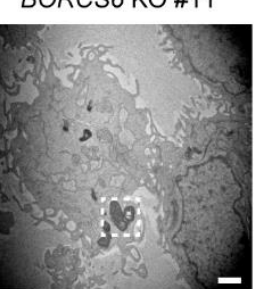

BORCS6 KO \#17

904

905

906
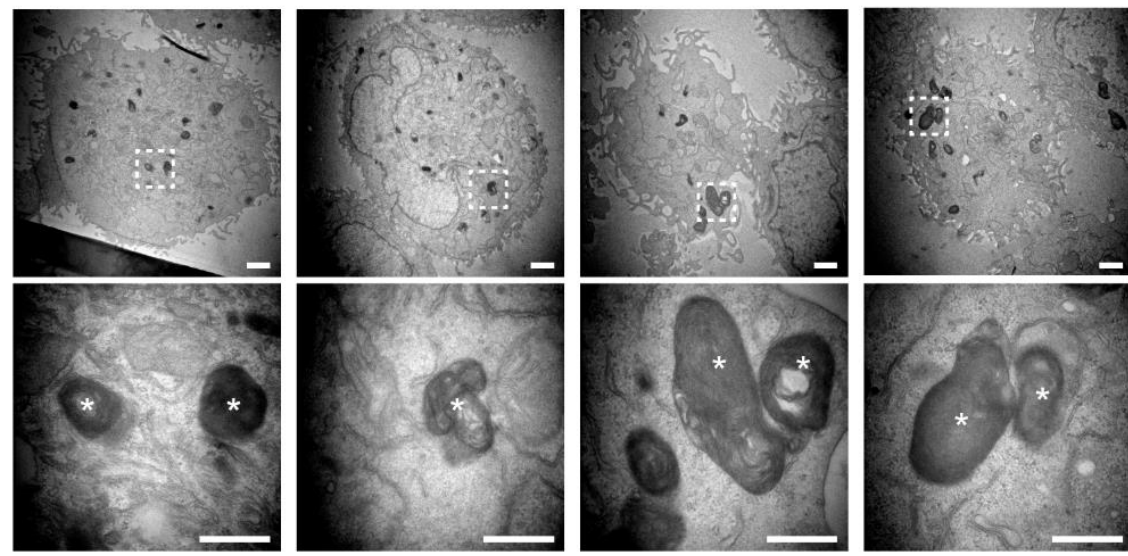

C

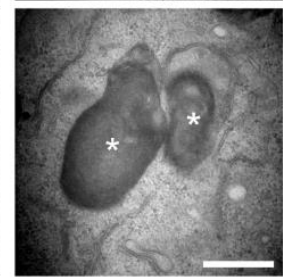

910

B
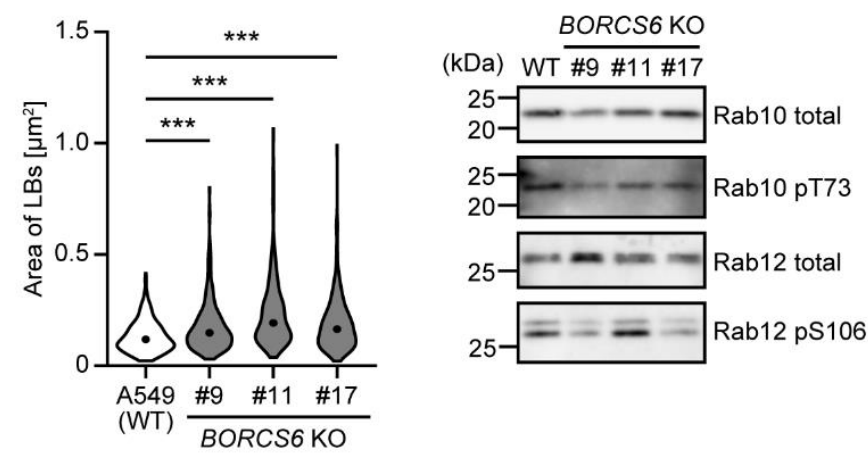

D

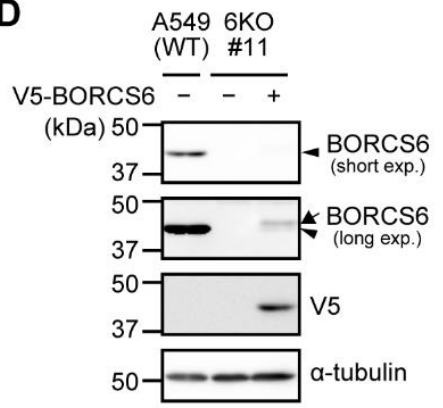

914

915

916

917

918

919

E

A549 (WT)

A549
BORCS6 KO \#11

A549
BORCS6 rescue
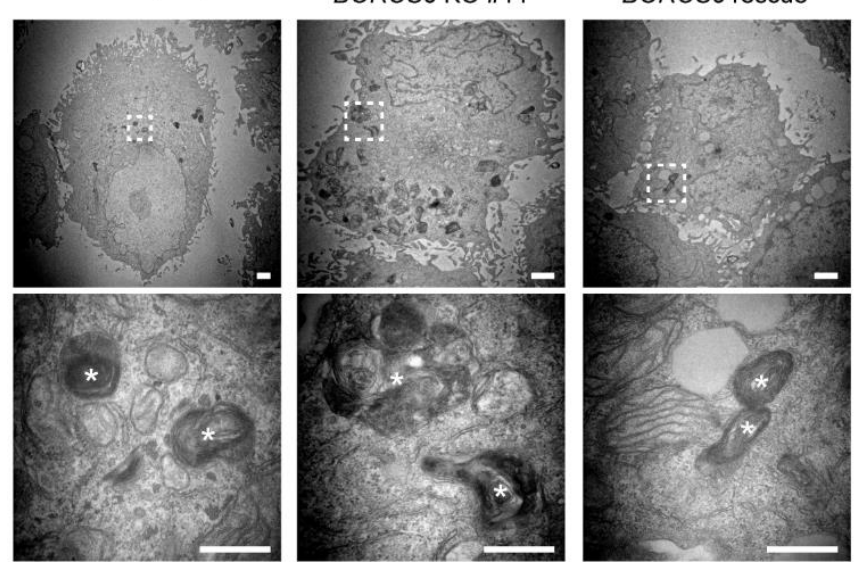

F

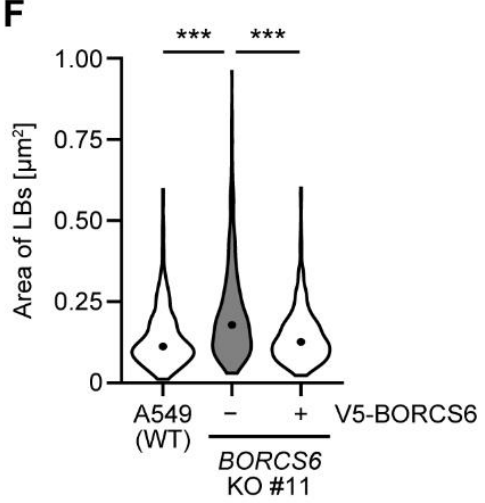

921

922

923

924

Figure 7

925 
bioRxiv preprint doi: https://doi.org/10.1101/2021.03.05.434068; this version posted March 5, 2021. The copyright holder for this preprint (which was not certified by peer review) is the author/funder, who has granted bioRxiv a license to display the preprint in perpetuity. It is made available under aCC-BY-NC-ND 4.0 International license.

926

927

928

934

935

936

937

938

Figure 8

\section{Wild-type}
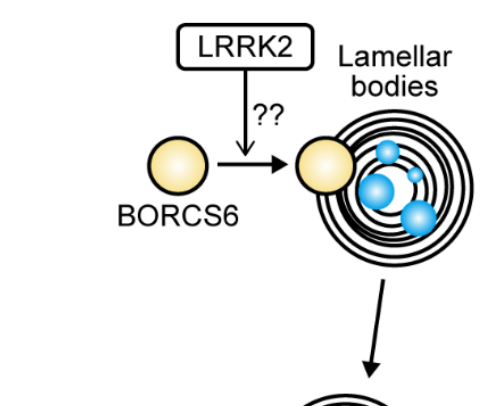

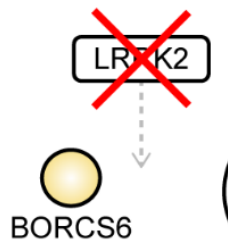
BORCS6

\section{LRRK2 KO}

Lamellar
bodies

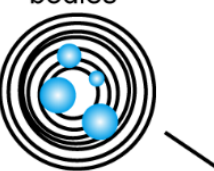

Enlarged

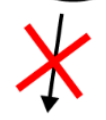

Impaired exocytosis 